\title{
Practical training for WALTER M601 engine
}

\author{
Ing. Martin Novák, Ph.D. \\ Department of Air Transport \\ CTU in Prague, Faculty of Transportation Sciences \\ Prague, Czech Republic \\ novakm@fd.cvut.cz
}

\author{
Bc. Jan Šlofar \\ Department of Air Transport \\ CTU in Prague, Faculty of Transportation Sciences \\ Prague, Czech Republic \\ xslofar@fd.cvut.cz
}

\begin{abstract}
This article provides an overview of practical work exercises for the WALTER M601B engine. The work exercises are divided into several sections, each being with description and it is accompanied by diagrams and images. This article explains each section in brief and refers to the thesis titled Practice training for WALTER M601 engine.
\end{abstract}

Keywords - WALTER M601, turboprop engine, maintenance, jigs, compressor, repair, combustion chamber, operation sheet, endoscopy

\section{INTRODUCTION}

The Faculty of Transportation received the turboprop engine Walter M601 from GE Aviation Czech s.r.o during the GE open day event on March $31^{\text {st }}$, 2011. The engine, together with the gift certificate, was handed over to the statuary representative of the Dean of the Faculty Prof. Ing. Tomas Zelinka, CSc by GEAC's commercial director Ing. Milan Slapak, Ph.D. The hand-over ceremony was attended by many students of the Czech Technical University in Prague.

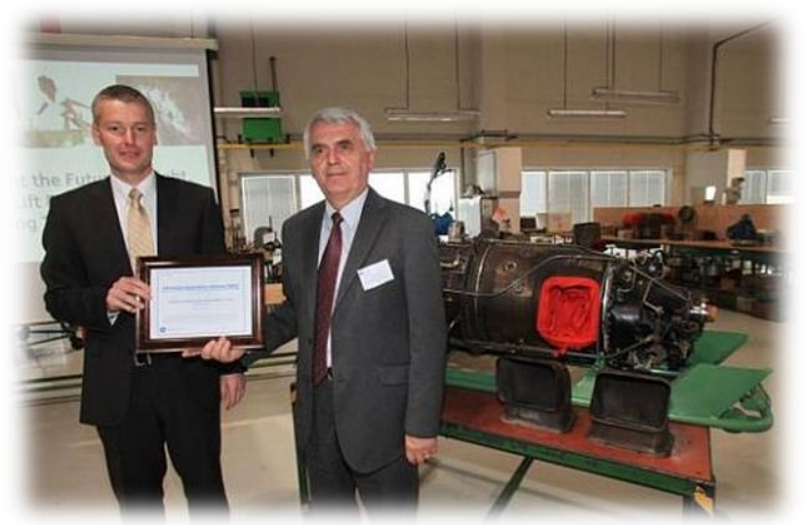

Figure 1. Prof. Ing. Tomáš Zelinka, CSc.receives the gift certificate and WALTER M601 engine from GEAC commercial director Ing. Milan Slapak PhD. [3]

The engine Walter M601 is mainly going to serve the needs of the Department of Air Transport and its students. After receiving the engine, there was a proposal to create new student materials for students in order to be more familiar with aviation technology from the practical point of view, specifically with turbo propeller engines, their systems, construction design, and maintenance practices.
It was necessary to consolidate information about tools to assemble and disassemble the engine, equipment, consumable material, as well as tools needed to store and move the engine. It was also necessary to create technological manuals accompanied by photos describing several types of repairs of the engine. These manuals must be highly detailed, so students are able to disassemble and assemble the engine using only these manuals and they do not need any additional technological documentation or catalogs.

\section{WALTER M601B ENGINE}

Walter M601 engine is a small turboprop engine with power turbine and is designed for use in small passenger, agricultural, and training aircrafts. The engine is equipped with a ramp for compressor washing, also used for water injection during high temperature performance.

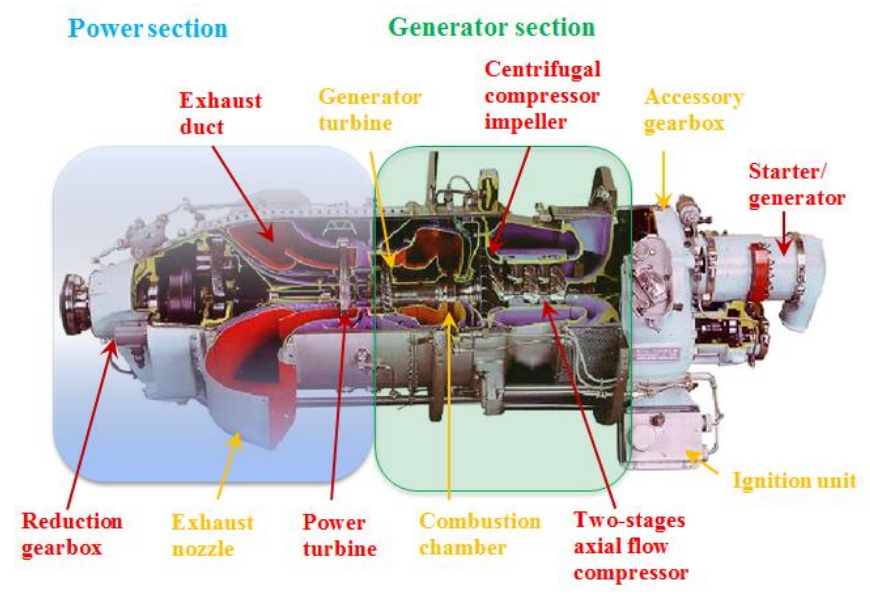

Figure 2. WALTER M601engine with descriptions [2]

The engine features two independent parts: the gas generator and the propulsion section. The gas generator and power turbine shafts are arranged in a tandem layout Air enters the engine in the rear part, flows forward through the compressor, combustion chamber, and turbines and exits through exhaust nozzles near the front of the engine.

\section{BASIC TECHNICAL SPECIFICATION}

Engine type: Turbo Propeller Engine in pull configuration, Two-Shafts with Power Turbine 
Propeller Shaft Configuration: Flanged

Direction of Rotation: (looking in a direct of flight)

Gas Generator Rotor - left

Power Turbine Rotor - left

Propeller Shaft - - right

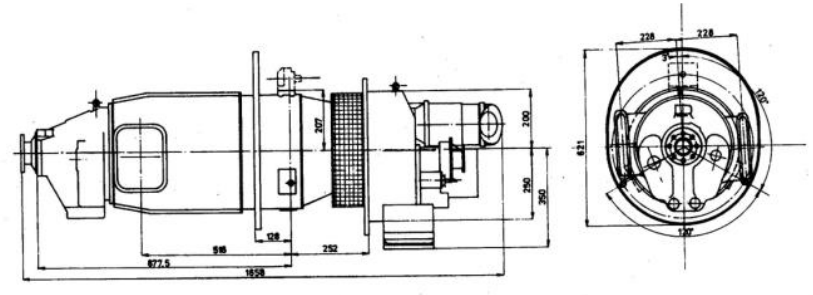

Figure 3. WALTER M601 engine dimensions ${ }^{[2]}$

Engine weight: Dry Engine weight (app.) $201 \mathrm{~kg}(443 \mathrm{lb})$

Oil Fill: $\quad 7 \mathrm{~kg}(15,4 \mathrm{lb})$

Fuel: $\quad$ Jet A, Jet A1

Oil: $\quad$ Oil consumption max. $0,1 \mathrm{l} / \mathrm{h}$

$(0,025 \mathrm{US}$ gal/h).

\section{PRACTICE TRAINING}

In order for the practical training to be beneficial for students, it was necessary to choose exercises which students are able to perform without previous training, but which also allow students to get to know the core parts of the engine and compare newly obtained information with information gained through classroom lectures.

For those reasons, the practical training includes operations performed only by the most experienced and trained technicians of the manufacturer. Although there are very complicated operations such as replacement of combustion liner or replacement of generator turbine blades, the instructions for these operations are described in so much detail, that there is no need for any additional training or knowledge.

A few operations have been chosen varying in the type of performed works as well as position of the engine:

\section{A. Practical training on engine in horizontal position}

Only one exercise has been chosen for this operation. However it is very interesting in terms of observing the transfer of power from the turbine to the propeller, speed reduction, and torque measurement.

„Front part of reduction gearbox replacement*“.

\section{B. Practical training on engine in vertical position}

The main part of the practical exercises involves engine split. This includes separation of exhaust part of the engine compartment from the generator part, followed by removal of hot section parts of the engine.

There are several exercises for this position:

- Outer combustion liner replacement*

- Inner combustion liner replacement*

- GT guide vane ring replacement*

- Dismounting and mounting of GT disc

\section{Practical training not dependent on the position of the engine}

Endoscopic inspection and hot section inspection were chosen as exercises not dependent on engine position.

Due to the lack of student experience with engine maintenance and the level of difficulty of chosen practical exercises, highly detailed picture instructions have been developed. The level of detail in these instructions practically prevents a situation where students make a mistake during engine disassembly or assembly. More information about these instructions is described in the section "Operation sheets."

\section{EQUIPMENT NECESSARY FOR PRACTICAL TRAINING}

The donated WALTER M601 engine came in a metal shipping container. The engine was mounted to a bracket inside the metal container.

In order to use the engine for practical exercises, it was necessary to create a mounting stand. It was also necessary to design or acquire equipment for dismantling the engine. The last phase of preparation was to calculate the amount of consumable material needed for reassembling the engine after disassembly. Consumable material includes lock washers for example. In order to make engine assembly quicker and to save on costs, it was necessary to replace all disposable consumable material with reusable material.

\section{A. Mounting Stand}

Mounting stand on which the engine would be placed had to be designed so it could be manufactured in a simple way, but it also had to fit through a door way $80 \mathrm{~cm}$ wide. As a result of these requirements, a mounting stand in which the engine is placed in a vertical position was drawn. This position is suitable for the majority of practical exercises on the engine.

The mounting ring was manufactured according to the drawings in SŠLVT Odolena Voda. The stand is welded and ready for color coating in the picture below. The stand might be assembled with wheels for easier manipulation.

\footnotetext{
* Not replacement of parts, for training purposes is suitable disassembly and reassembly of the same part
} 


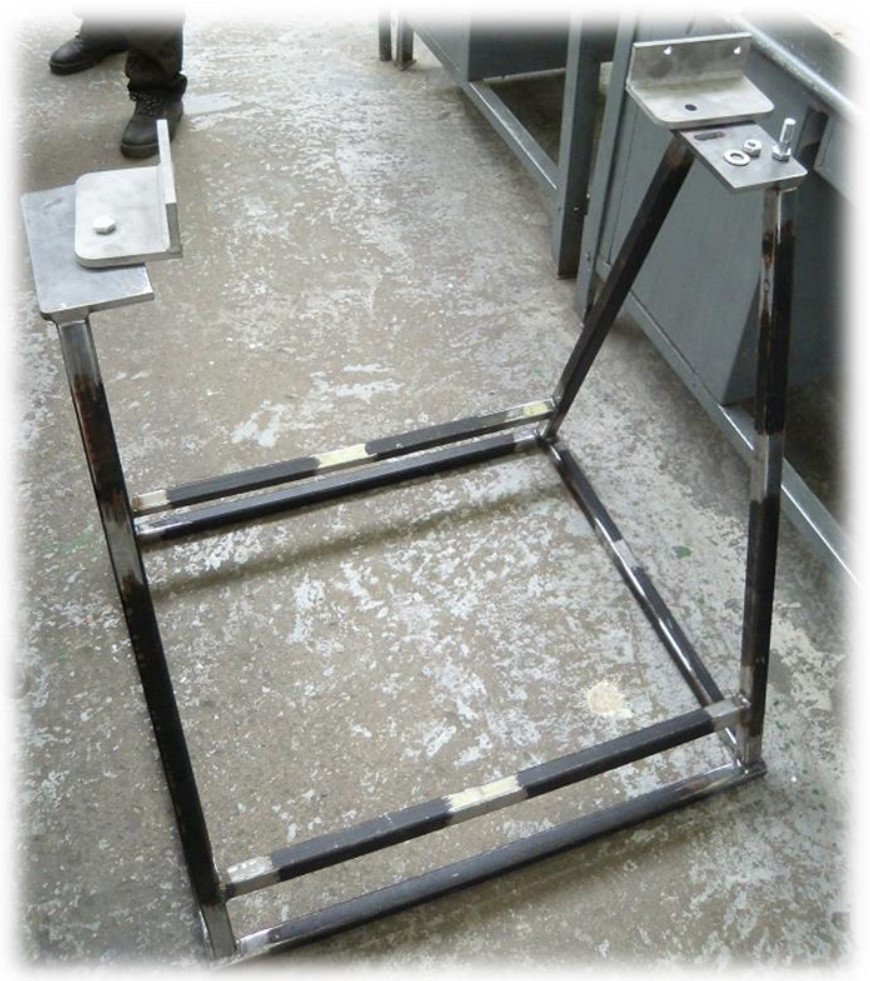

Figure 4. Mounting stand before color coating

\section{B. Crane, lifting equipment}

The weight of dry engine is approximately $200 \mathrm{~kg}$. This weight makes manual manipulation with the engine very difficult.

There is need for a crane when performing the practical exercises and lifting the engine up.

A crane is first needed when moving the engine from the shipping container onto the mounting stand. Secondly, and more often, a crane is needed during disassembly of the engine. In the case of engine disassembly, it is necessary to split the engine and lift a half of the engine up and secure it elsewhere while the other half of the engine stays on the stand for further dismantling.

A crane with manual hoist, width of $3000 \mathrm{~mm}$, height of $4000 \mathrm{~mm}$, and minimum capacity of $250 \mathrm{~kg}$ serves this purpose very well.

\section{Jig for connecting the propeller shaft to the lifting equipment}

As the name suggests, this is a product that allows us to connect lifting equipment (crane) to the flange of the propeller shaft.

Due to technological intensity to produce the official jig equipment, it was necessary to find a different solution. New and considerably simpler solution is pre-bent rod in the size of $\varnothing 14 \mathrm{~mm}$ and threads on both ends with M14 nuts and washers.
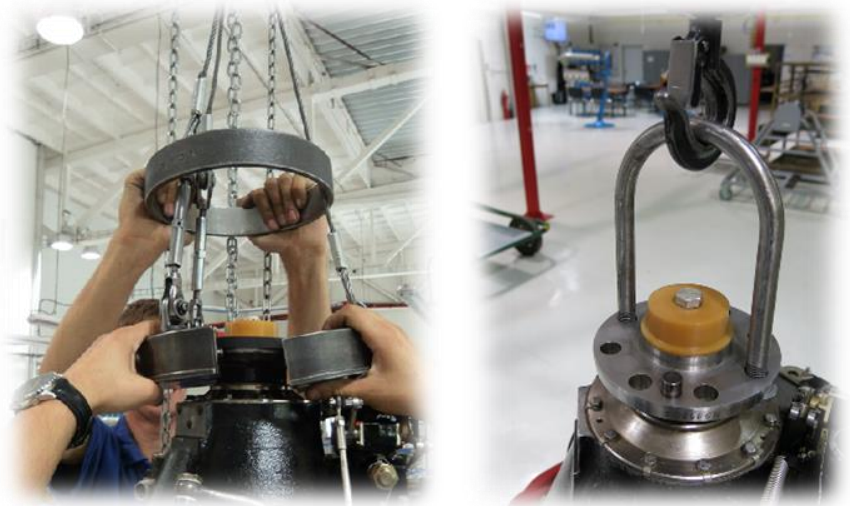

Firuge 5. The original equipment (left) and new equipment for connecting the propeller shaft to the lifting equipment

\section{Jig for preventing rotation of the generator turbine}

Jig prevents spinning of the rotor during unscrewing of the generator turbine. This equipment embraces rear shaft and is attached to the flange casing of the radial compressor.

Similarly to the mounting stand, this product was manufactured in SŠLVT Odolena Voda.

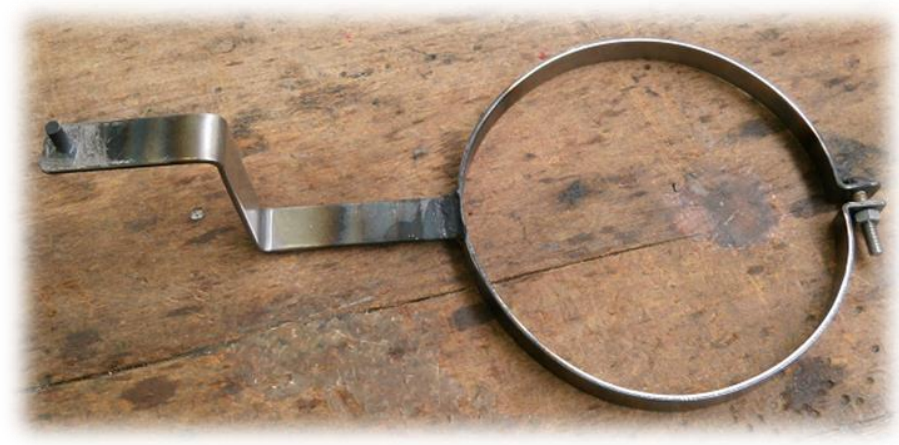

Figure 6. Jig to prevent rotation of the generator turbinemanufactured in SS̆LVT Odolena Voda

\section{E. Jig for pulling the generator turbine}

Jig allows removal of the generator turbine disk from the main shaft.

Jig is attached to the flange case of radial compressor. The hole in the axis of rotation of the disk is inserted with a pin that is attached to this product. While rotating the handle attached to the thread, the pin is inserted into the spring collet that consequently expands. The disc of the turbine can then be screwed out.

\section{ENGINE MODIFICATION For TRAINING PURPOSES}

Engine modification is mainly done through the use of lock washers, seals, and seal coatings. The engine will be modified during the first practice session. All lock washers will be replaced during this first exercise. There are four pieces on the transmitter flange (size 6.2), six pieces on the flange of electro-hydraulic actuator (size 6.2), two pieces on pipe flanges on the air-in pipe (size 5.2), two pieces on the reducer for oil pipe (sizes 5.2), twelve pieces to cover the roller 
bearings and 36 pieces on the flange of the power turbine (both size 5.2).

\section{OPERATION SHEETS}

Operation sheets were the most important part of the project and there were many unknowns during their creation. Their preparation took almost two years. It was necessary to be fully familiar with the WALTER M601 engine and its maintenance procedures and technological processes. From the beginning, it was planned to create such procedures which would allow very difficult repairs to be handled by inexperienced technicians or students.

There was an effort to find information about similar operation sheets intended for other types of engines, or other technological devices that would serve as a starting point and source of inspiration.

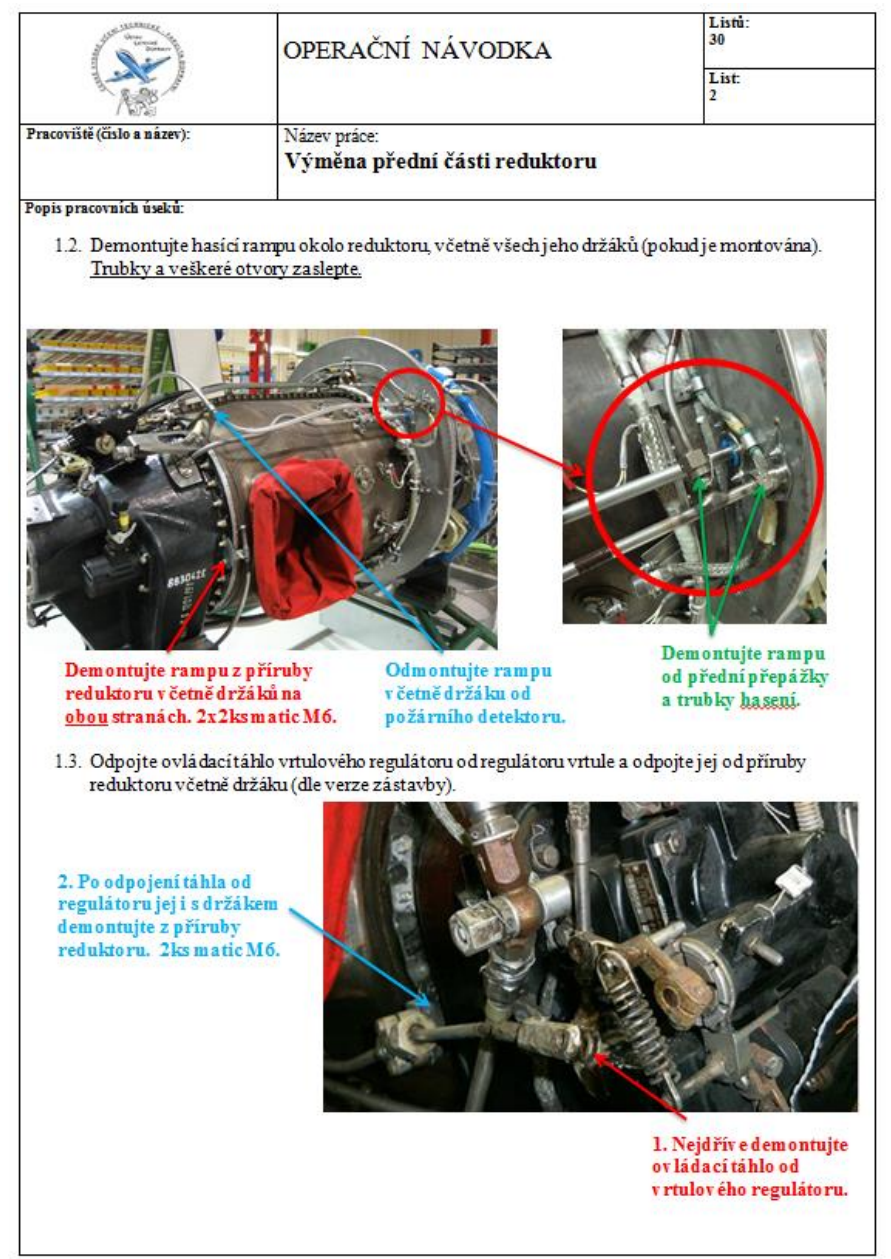

Figure 7. Illustration operation sheets

After a while, it was realized that technological procedures written for such complex operations that are described in Chapter IV, are very complex and written only in highly technical language for trained professionals with years of experience. An inexperienced person is not able to perform good job following such procedures.
This project then took on the challenge to create technological procedures in a brand new and non-standard way. While creating these procedures, over 13500 pages of technical documentation had been read and 1077 photographs had been taken. The result is a document of 400 pages that describes procedures for the WALTER M601 engine in an extremely high detail.

\section{A. Operation sheets content}

Operation sheet contains primarily technological processes accompanied by images to navigate through a work procedure. In addition, there is the name and chapter number in front of each technological process, followed by the reason of creation and a brief description of the work. Furthermore, each chapter contains a list of tools and materials needed for each job. The last row contains information about the conditions prescribed for the work procedure, instructions for technicians and their inspection, and guidance for safety procedures.

\section{B. Operation sheet sample}

Text and images for the technological process are on each page inserted into a table, which contains the name of the work procedure, number of pages, and the number of the specific page. There is also information about the work, the name "Operation sheet" and logo of the Department of Air Transport, Faculty of Transportation Sciences. In the footer of each sheet is the following statement: "Exclusively for use by students of the Faculty of Transportation Sciences and needs of the aviation FD CTU". The rest of the worksheet contains space for technological procedures of the operation.

\section{CONCLUSION}

The project dealt with practical exercises on the WALTER M601 engine as a whole. It describes all the necessary equipment for practical exercises of each technological procedure.

Due to absence of any practical exercises on this type of engine, the primary purpose of this project was to think about the individual working procedures that workers (students of CTU) could deal with. The result is six working procedures of different difficulty demanding anywhere from 2 to 20 hours of labor. Working procedures are divided into categories based on the position the engine needs to be in.

Furthermore, technological procedures were developed for each work operation. Although technological procedures for removal and installation of the engine are described in the manual for general overhaul, there are only procedures for complete disassembly or assembly of the engine, not procedures for partial engine repairs. In addition, these procedures are developed for professionals with several years of service work experience, and are therefore very difficult to understand and follow. For these reasons, a student, as a more theorist, would not able to fulfill all processes in a work procedure. Therefore, new and user friendly operational instruction cards for each operation were created. Each instruction contains the name of the operation, instructions for technicians and their inspection, conditions for the operation, list of tools, equipment, consumable material, and instructions 
for safety. Technological processes are accompanied by images with annotations, which make it possible for even the most complex works to be performed by a worker with only a theoretical basis for assembling a turbine engine.

Lastly, it was necessary to obtain necessary equipment in order to fulfill the individual work procedures. This equipment includes all the special tools, reusable consumable material, as well as the engine stand. Some of these products have been designed and manufactured from scratch. Some were manufactured based on original documentation and adjusted for training purposes.

The production of special equipment and tools, for which drawings were supplied, was done together with the SŠLVT Odolena Voda.

While instruction cards, including the technological procedures, are designed specifically for students of the Faculty of Transportation Sciences, the document describing practical exercises on the WALTER M601 engine serves as the basis for the "owner" of practical exercises and the instructors (for Department of Air Transport, lecturers, instructors and trainers) .

A moderate reader reading the work can obtain a general overview of the history, function, and preparation of the WALTER M601 engine for practical exercises, as well as procedures behind individual operations.

\section{REFERENCES}

[1] J. Šlofar, "Diplomová práce Praktické cvičení na motoru WALTER M601,” Praha, Duben 2013. 174 s.

[2] "Walter M601 turboprop engine maintenance training manual," Praha: GE AVIATION CZECH s.r.o., 2008. cca 350 s.

[3] "Předání motoru M 601 Fakultě dopravní," Internetový článek, Praha: FD ČVUT v Praze, 31.3.2011. Dostupné z WWW: <http://www.fd.cvut.cz/kalendar-udalosti/fakulta-v-mediich.html 